\title{
技術論文
}

\author{
치사율 평가를 위한 공대공 미사일 모의 발사 프로그램 개발 \\ 성재민*, 김병수**, 신보현***

\section{Development of a Air-to-Air Missile Simulation Program for the Lethality Evaluation}

Jaemin Sung*, Byoung Soo Kim** and Bo Hyun Shin***

\begin{abstract}
This paper presents to calculate the lethality of missile for the simulation test program and to verify the simulation results. In order to calculate a reliable lethality we need may data and experiments of fuse and warhead, but in reality it is hard to perform a task. Therefore, this paper obtained from the reference paper to analyze the lethality data for the calculation of the lethality. We form the 6 DOF simulation model using the MATLAB/SIMULINK. And formed the autopilot algorithm using the vertical and horizontal acceleration feedback and PNG (Proportional Navigation Guidance) command be used to the guidance algorithm. Finally, we evaluate the results about three cases, front launch, side launch and rear launch to simulate the simulation program, and the target is designed to have a constant speed and direction.

\section{초 록}

본 논문은 장 단거리 공대공 미사일의 치사율을 계산하고, 대상 미사일의 모델을 구성 하여 모의 발사 시험 프로그램을 개발하고자 한다. 신뢰성 있는 치사율을 계산하기 위해 서는 신관과 탄두에 대한 많은 자료와 실험이 필요하지만 현실적으로 그런 작업을 수행 하기엔 한계가 있다. 따라서 본 논문에서는 참고문헌[3-6]에서 획득한 치사율에 대한 자료 를 분석하여 치사율을 계산하였다. 모의시험을 위한 시뮬레이션 프로그램은 MATLAB/SIMULINK를 이용하여 $6 \mathrm{DOF}$ 시률레이션 모델을 구성하였으며, 수직, 수평 가속도 피드백을 이용한 자동비행 알고리즘과 PNG(Proportional Navigation Guidance)을 이용한 유도명령 알고리즘, 그리고 시간지연과 오차를 고려한 탐색기(seeker)의 동적 모델 을 구성하여 적용하였다. 최종적으로 정면발사, 측면발사, 후면발사의 3 가지 경우에 대하 여 모의 비행을 수행하여 결과를 정리하였으며, 이때 목표물은 일정한 방향을 가지고 등 속비행을 하는 것으로 설계하였다.
\end{abstract}

Key Words : Lethality(치사율), Missile Simulation(미사일 시뮬레이션), Air-to-Air Missile(공대공 미사일)

†2009년 12월 8일 접수 2010년 1월 19일 심사완료

* 정회원, 경상대학교 항공우주공학과 대학원

** 정회원, 경상대학교 기계항공공학부(ReCAPT) 교신저자, E-mail : bskim@gnu.ac.kr 경남 진주시 가좌동 900 번지

*** 정회원, 건국대학교 항공우주정보시스템공학과

\section{I. 서 론}

공대공 유도무기체계의 획기적인 발전으로 공 중전 공격 능력은 비약적으로 향상되고 있으며, 전투기 조종사의 공중전투 능력향상은 필수불가 
결의 요소가 되었다. 그러나 현실적으로 공중전 투 훈련에서 가상 적기에 대해 실제로 미사일을 발사할 수 없기 때문에 미사일 모의발사 시뮬레 이터가 필요하다. 현재는 초기 발사 시 목표물의 좌표를 미리 계산된 치사율 데이터에 적용하여 계산하는 Missile Launch Envelope System 방법 [1]이 사용되고 있으며, 이는 목표물의 회피기동 으로 인한 변화를 고려할 수 없을 뿐만 아니라 모든 상황에 대한 치사율 계산을 $\mathrm{DB}$ 로 구축하는 것은 불가능하기 때문에 현실성이 떨어진다.

반면 공중전투 훈련에서 미사일을 발사한 후, 미사일과 가상의 적기의 움직임 및 회피 기동을 시뮬레이션 하여 치사율을 계산하는 Fly-out Simulation 방법[1]이 있는데, 이는 치사율 계산 의 현실성을 높이는 동시에 미사일과 적기의 비 행경로를 조종사에게 보여 줄 수 있는 장점이 있 다.

Fly-out Simulation의 경우 비행제어 컴퓨터의 부하가 많이 걸리는 단점이 있지만, 오늘날 비행 제어 컴퓨터의 발달로 충분히 수행할 능력이 된 다고 판단되며 따라서 본 논문에서는 Fly-out Simulation 을 개발하고자 한다.

따라서 본 논문에서는 미사일의 비선형 모델 을 사용하여 시뮬레이션 프로그램을 구성하였으 며, 이때 목표물은 특정 위치에서 일정한 속도로 비행한다고 가정하여 구성하였다. 치사율은 목표 물과 조우 시 상대속도 상대거리, Angle-off를 고 려하여 계산하였으며, 이를 시뮬레이션 모델에 적용하여 그 결과를 확인하고자 한다.

\section{ㅍ. 본 론}

\section{1 대상 미사일 제원 및 모델링}

본 연구를 위해 그림 1 , 표 1 과 같은 제원 및 성능을 가지고 있는AIM-120 모델을 선택하였으 며, 대상 시스템의 비선형 공력 모델은 Missile $\mathrm{DATCOM}$ 을 사용하여 획득하였다. 추력모델은 그림 2에서 보듯이 참고자료를 통해 획득한 자료 를 바탕으로 예상 운항고도 $6 \mathrm{~km}$ 에서의 온도에 맞게 선형 보간을 사용하여 계산하였다.

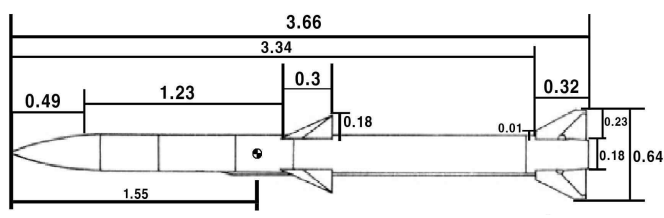

Fig. 1. AIM-120B 주요제원 (단위: m)
Table 1. AIM-120B 주요 성능 및 특성

\begin{tabular}{|c|c|c|}
\hline \multicolumn{2}{|c|}{ 구분 } & 내용 \\
\hline \multicolumn{2}{|c|}{ 신관 } & 근접 및 접촉 \\
\hline \multicolumn{2}{|c|}{ 유도방식 } & 능동레이더 \\
\hline \multicolumn{2}{|c|}{ 조종면 변위각 } & $\pm 15^{\circ}$ \\
\hline \multirow{2}{*}{ 추진제 } & 연소시간(초) & $6 \sim 8\left(-65 \sim 145^{\circ} \mathrm{F}\right)$ \\
\hline & 블록형상 & 성형(추정) \\
\hline \multicolumn{2}{|c|}{ 최대속도(Mach No.) } & 4.0 \\
\hline \multicolumn{2}{|c|}{ 기동력 $(\mathrm{g})$} & 35 \\
\hline \multicolumn{2}{|c|}{ 유효사거리 $(\mathrm{km})$} & 64 \\
\hline
\end{tabular}

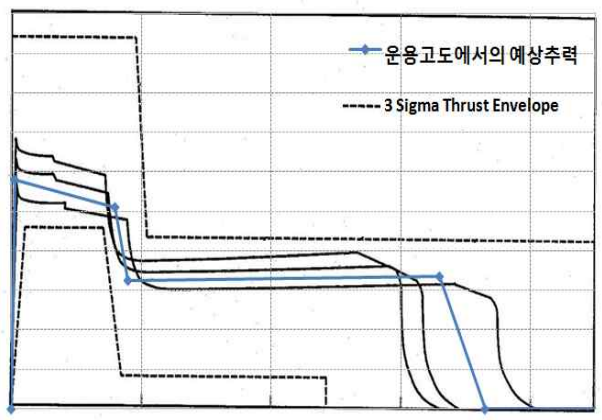

Fig. 2. Thrust Profile of AIM-120

AIM-120 모델의 경우 초기 발사각을 가지고 발사되어 유도되는 시스템으로 본 논문에서는 $45^{\circ}$ 의 발사각을 가진다고 가정하였다.

\section{2 유도 제어 알고리즘 구성}

대상 시스템의 자동비행 알고리즘은 고전제어 를 이용하여 구성하였으며, 게인은 속도에 따라 체계적으로 스케줄링 하였다. 자동비행 알고리즘 은 가속도 피드백을 이용한 종축과 방향축 제어 기를 설계하였고, 롤각 피드백을 이용한 횡축 제 어기를 설계하였다. 그림 3은 종축 제어기를 설 계한 모습이며, 그림 4는 횡축 제어기를 설계한 모습이다. 해당 제어기법은 보편적으로 사용되어 왔고, 참고문헌[2]에서 확인 할 수 있으므로 본 논문에서는 자세한 설명은 생략하기로 한다.

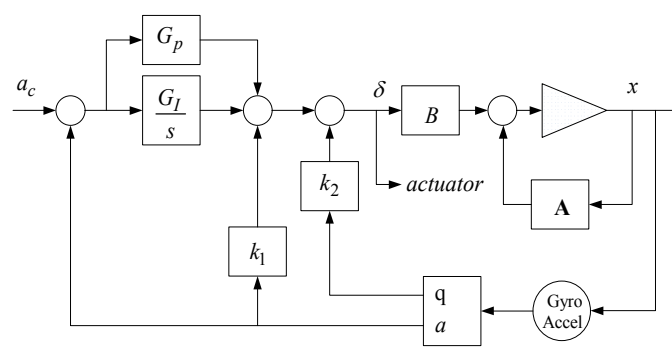

Fig. 3. 수직 가속도 제어 알고리즘 


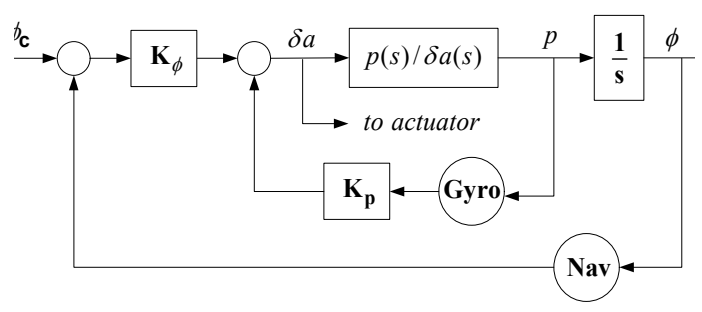

Fig. 4. 롤 자세각 유지 알고리즘

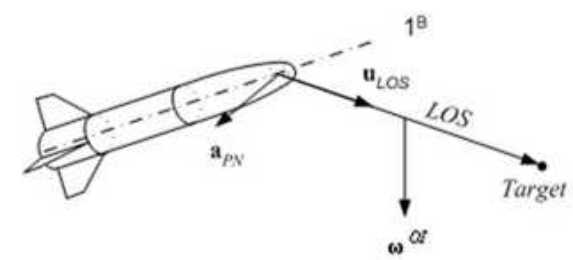

Fig. 5. 일반적인 PNG 방법

대상 시스템의 유도명령은 일반적인 $\mathrm{PN}$ Guidance를 사용하여 구성하였으며 중기유도와 종말유도로 구분하여 설계하였다.

중기유도는 식 (1)과 같이 상대속도가 일정하 다는 가정 하에 정리하였으며, 그림 5는 각 변수 의 물리적 의미를 나타낸다.

$$
\begin{aligned}
& \bar{a}=N V \bar{\Omega}^{O I} u_{L O S}-\bar{g} \\
& N: \text { Navigationgain } \\
& V: \text { Closing Speed } \\
& \bar{\Omega} \text { OI : Iertial angularvelocitiy } \\
& \bar{g}: \text { Gravityterm }
\end{aligned}
$$

종말 유도는 목표물과 조우 시 발생하는 가속 도 변화를 고려하여 식 (2)와 같이 수정된 가속 도 명령을 계산하였으며 그림 6 에서 각 변수의 물리적 의미를 확인할 수 있다.

$$
\begin{aligned}
& \bar{a}=N V \bar{\Omega}{ }^{O I} u_{L O S}-\bar{a}_{m o}-\bar{g} \\
& \bar{a}_{\text {mo }}=\bar{P}_{\text {LOS }} \bar{a}_{m} \\
& \bar{a}_{\text {mo }}: \text { Velocity decay term } \\
& \bar{P}_{\text {LOS }}: \text { Projection tensor }
\end{aligned}
$$

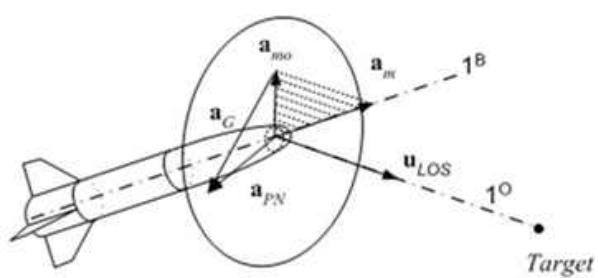

Flg. 6. 보완된 PNG 방법
유도명령에 대한 자세한 내용은 참고문헌[2]를 통해 확인 할 수 있으므로 자세한 설명은 생략하 기로 한다.

\section{3 공력 계수 보정}

앞서 설계한 유도 제어 알고리즘을 적용하여 시뮬레이션을 수행한 결과 기존의 알고 있던 대 상 미사일의 성능과 상이했다. 따라서 대상 미사 일의 성능에 결정적인 영향을 미치는 공력계수를 참고자료를 통해 획득한 값을 기준으로 비교하여 수정하였다. 이때 참고자료는 보안이 요구되는 자료로 참고문헌에 기록하지 않았으며, 구체적인 수치 역시 삭제 하였으므로 이점 양해를 구한다.

그림 7에서 보듯이 DATCOM을 사용하여 획 득한 항력계수가 기준 값에 미치지 못함을 확인 할 수 있다. 항력의 경우 대상 시스템의 비행 거 리에 영향을 주는 주요 요소이므로 이를 기준 값 과 유사한 값을 가지도록 각 트림속도별로 항력 계수를 보정하였다.

표 2는 대상 시스템의 기동영역을 정리한 것 으로써, DATCOM을 사용하여 획득한 수정 전의 모델의 경우 기준 값에 비하여 기동 범위가 매우 작음을 알 수 있다. 따라서 이를 보정하기 위하 여 식(3)과 같이 피칭 모멘트와 요잉 모멘트의 조종면 변위에 대한 공력계수의 변화량을 1.6 배 증가 시켰다. 그 결과 기준 값과 일치하지는 않 지만 대상 시스템의 기동 범위를 커버 할 수 있 는 시스템을 구성 하였다.

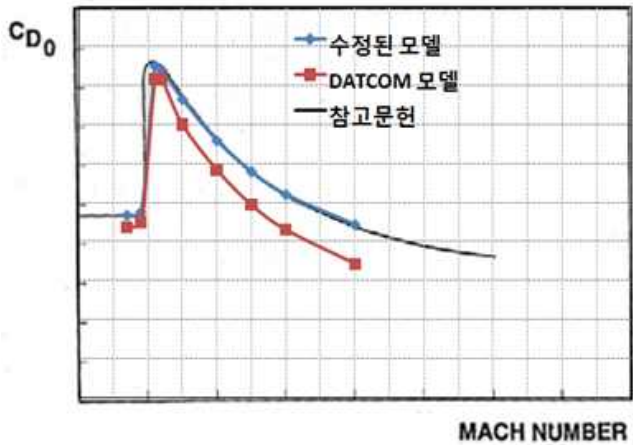

Fig. 7. Modified Drag Coefficient

Table 2. 대상 미사일 기동성능 비교

\begin{tabular}{|c|c|c|c|}
\hline \multirow{2}{*}{ 마하수 } & \multicolumn{3}{|c|}{ 기동 범위 $(\mathrm{g})$} \\
\cline { 2 - 4 } & 참고자료 & 수정 전 & 수정 후 \\
\hline 0.8 & 3 & 1 & 4 \\
\hline 1.0 & 5 & 2 & 7 \\
\hline 1.2 & 7 & 3 & 13 \\
\hline 1.6 & 27 & 5 & 22 \\
\hline
\end{tabular}




$$
C m=C m_{0}+1.6 \Delta C m_{d p}, \quad C n=C n_{0}+1.6 \Delta C n_{d y}
$$

\section{4 치사율 계산}

참고문헌 [4]에서의 $\mathrm{AIM}-120$ 의 교범 작성 시 기, 참고문헌 [5]에서의 치명반경, 참고문헌 [6]에 서의 신관의 탐지 범위에 대한 자료와 비교하여 보았을 때 참고문헌[3]의 치사율에 대한 자료가 AIM-120의 치사율에 대한 자료로 추정하였으며 본 논문의 치사율 계산의 근거자료로 활용한다.

앞에서 제시한 근거를 바탕으로 AIM-120의 상 대거리에 대한 치사율을 그림 8과 같이 도출하였 다. 치사율은 Miss distance에 따라서 5 개의 구간 으로 나누어 다항식으로 구성하였으며, Miss distance는 미사일과 목표물의 상대거리가 감소 하다가 증가하는 순간의 거리를 의미한다.

치사율은 그 정도에 따라 $\mathrm{K}-\mathrm{Kill}(30$ 초 이내 조 종불능), A-Kill(5분 이내 조종불능), B-Kill(30분 이내 조종불능)로 나눠서 표현된다.

그림 9는 접근방위각(Angle off)과 추월속도에 대한 치사율을 나타내는 그래프로 방위각 보정은 $0^{\circ} 180^{\circ}$ 접근 방위각의 치사율 평균값(약 $77 \%$ )을 기준으로 최종 접근 방위각의 치사율과 평균값의 차이를 그림 8의 값에 가감하여 보정하였다.

추월속도에 따른 치사율 값은 접근 방위각의 치 사율 평균값에 해당하는 추월속도 (약 $400 \mathrm{~m} / \mathrm{s}$ )를 기준하여 최종 추월속도에서의 치사율과 평균값 의 차이를 그림 8 의 값에 가감하여 보정하였다.

접근방위각에 대한 치사율 데이터는 기울기가 변하는 지점을 구간으로 나누어 선형식으로 표현 하였으며, 추월속도에 대한 치사율 데이터는 하 나의 선형식으로 표현하였다.

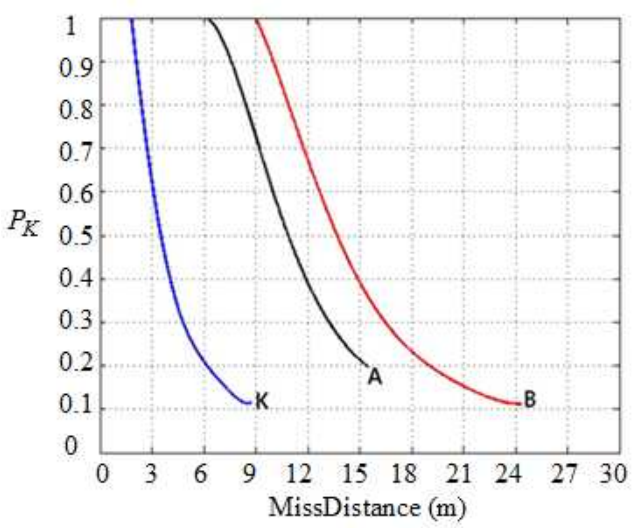

Fig. 8. AIM-120B의 Miss Distance에 따른 치사율
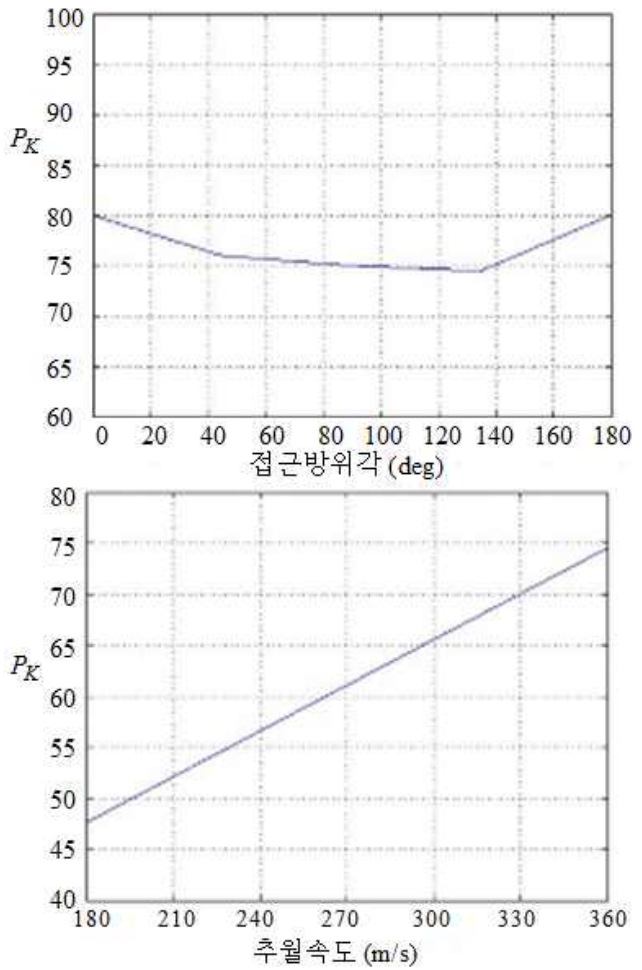

Fig. 9. 접근각(상)/추월속도(하)에 따른 치사율

여기서 접근방위각은 목표물과 미사일의 헤딩 각의 차이를 나타내며 추월속도는 상대속도를 의 미한다.

\section{5 시뮬레이션 결과}

설계된 시뮬레이션 모델에 치사율 계산 알고 리즘을 적용하여 시뮬레이션을 수행하였다. 시뮬 레이션은 크게 정면, 후면, 측면 발사에 대하여 수행하였으며, 대표적인 결과만 본 논문에 수록 하기로 한다. 시뮬레이션 결과에서 보듯이 3 가지 경우 모두 치사율이 $100 \%$ 로 나왔으며 이때 전체 치사율은 $\mathrm{B}, \mathrm{A}, \mathrm{K}-\mathrm{Kill}$ 일 때의 각각의 치사율을 합한 값이다. 시률레이션의 경우 목표물의 회피 기동 및 외란 등에 의한 영향이 없으므로 미사일 의 비행거리에만 들어온다면 치사율이 매우 높게 나오는 것으로 판단된다.

Case 1) 정면 발사

정면발사는 미사일과 목표물이 마주보는 상황 에서 발사된 경우이며, 표 3 과 같은 초기조건을 가지고 수행하였다. 그림 10 에서 보듯이 미사일 이 목표물을 격추한 것을 확인할 수 있으며, 그 때의 접근속도, 접근방위각, 상대거리와 이를 통 해 계산된 치사율을 표 4에서 확인할 수 있다. 
Table 3. 미사일 및 목표물 초기 조건

\begin{tabular}{|c|c|c|c|}
\hline 항목 $($ 단위 $)$ & 미사일 & Target & 기준축 \\
\hline 속도 $(\mathrm{m} / \mathrm{s})$ & {$[284,0,17]$} & {$[253,0,0]$} & Body \\
\hline 위치 $(\mathrm{km})$ & {$[0,0,6]$} & {$[80,0,6]$} & Inertial \\
\hline 자세각 $(\mathrm{deg})$ & {$[0,45,0]$} & {$[0,0,180]$} & Body \\
\hline
\end{tabular}

Table 4. Case1) 치사율 및 관련 파라미터

\begin{tabular}{|c|c|c|c|}
\hline 항목 & $\mathrm{Pk}(\%)$ & 항목 & 값 \\
\hline B-Kill & 0 & 접근속도 & $521.0 \mathrm{~m} / \mathrm{s}$ \\
\hline A-Kill & 0 & Angle off & $154.6^{\circ}$ \\
\hline K-Kill & 100 & Miss dist. & $0.0 \mathrm{~m}$ \\
\hline
\end{tabular}

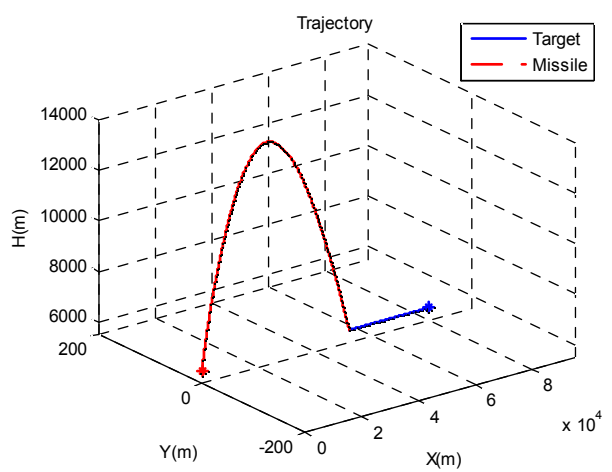

Fig. 10. Case 1) 시뮬레이션 결과

Case 2) 후면 발사

후면발사는 미사일이 목표물의 후방에서 발사 된 상황이며, 표 5의 초기조건을 가지고 수행되었 다. 그림 11 과 표 6 에서 결과를 확인 할 수 있다.

Table 5. 미사일 및 목표물 초기 조건

\begin{tabular}{|c|c|c|c|}
\hline 항목 $($ 단위 $)$ & 미사일 & Target & 기준축 \\
\hline 속도 $(\mathrm{m} / \mathrm{s})$ & {$[284,0,17]$} & {$[253,0,0]$} & Body \\
\hline 위치 $(\mathrm{km})$ & {$[0,0,6]$} & {$[15.3,0,6]$} & Inertial \\
\hline 자세각 $(\mathrm{deg})$ & {$[0,45,0]$} & {$[0,0,0]$} & Body \\
\hline
\end{tabular}

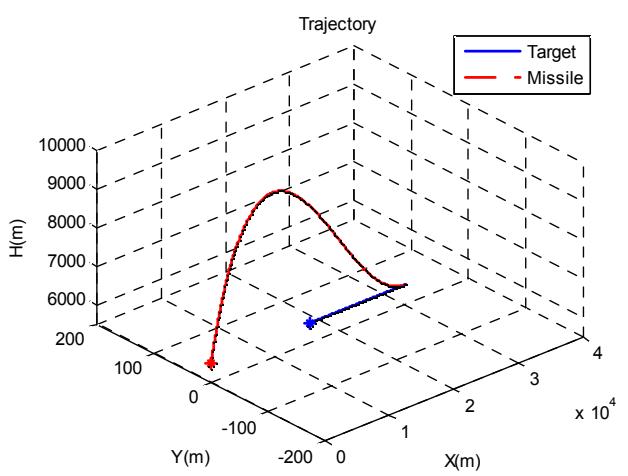

Fig. 11. Case 2) 시뮬레이션 결과
Table 6. Case 2) 치사율 및 관련 파라미터

\begin{tabular}{|c|c|c|c|}
\hline 항목 & Pk $(\%)$ & 항목 & 값 \\
\hline B-Kill & 0.0 & 접근속도 & $4 \mathrm{~m} / \mathrm{s}$ \\
\hline A-Kill & 74.4 & Angle off & $0.6^{\circ}$ \\
\hline K-Kill & 25.6 & Miss dist. & $3 \mathrm{~m}$ \\
\hline
\end{tabular}

Case 3) 측면 발사

측면발사는 미사일이 목표물의 측면에서 발사 된 상황이며, 표 7의 초기조건을 가지고 수행되었 다. 그림 12 와 표 8 에서 결과를 확인 할 수 있다.

Table 7. 미사일 및 목표물 초기 조건

\begin{tabular}{|c|c|c|c|}
\hline 항목 $($ 단위 $)$ & 미사일 & Target & 기준축 \\
\hline 속도 $(\mathrm{m} / \mathrm{s})$ & {$[284,0,17]$} & {$[253,0,0]$} & Body \\
\hline 위치 $(\mathrm{km})$ & {$[0,0,6]$} & {$[20,0,6]$} & Inertial \\
\hline 자세각 $(\mathrm{deg})$ & {$[0,45,0]$} & {$[0,0,-90]$} & Body \\
\hline
\end{tabular}

Table 8. Case 3) 치사율 및 관련 파라미터

\begin{tabular}{|c|c|c|c|}
\hline 항목 & $\mathrm{Pk}(\%)$ & 항목 & 값 \\
\hline $\mathrm{B}-\mathrm{Kill}$ & 45.76 & 접근속도 & $162.0 \mathrm{~m} / \mathrm{s}$ \\
\hline $\mathrm{A}-\mathrm{Kill}$ & 41.03 & Angle off & $33.7^{\circ}$ \\
\hline K-Kill & 13.21 & Miss dist. & $6.3 \mathrm{~m}$ \\
\hline
\end{tabular}

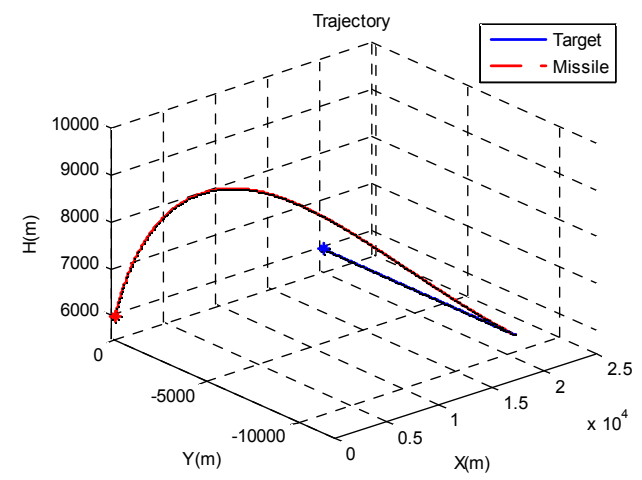

Fig. 12. Case 3) 시뮬레이션 결과

\section{III. 결 론}

본 논문은 공대공 미사일을 사용한 공중전의 중요성을 인식하고, 이에 합당한 훈련체계가 갖 춰지지 않은 국내 여건을 개선시키는데 도움이 되고자 치사율을 적용한 $\mathrm{Fly}-\mathrm{out}$ Simulation을 개발을 목표로 하였다. 실질적이고 정확도 높은 치사율을 획득하기 위해서는 탄두의 특성, 신관 의 시간지연의 영향, 피격체의 취약지점 등 수많 은 시험과 데이터가 축적이 되어야 가능하지만, 이와 같은 자료를 획득하기는 거의 불가능할 뿐 
만 아니라, 국내의 여건상 이와 같은 시험을 수 행하기에는 무리가 있다. 따라서 본 논문에서는 대상 미사일의 치사율에 관한 기본적인 자료를 획득 하였으며, 이 데이터를 분석 및 유추하여 원하는 관계식을 찾았다.

또한 DATCOM을 이용하여 대상 시스템의 $6 \mathrm{DOF}$ 비선형 모델을 구현하였으며 참고자료와 성능 비교를 통해 공력 모델을 보완하였으며, 자 동 유도제어 비행을 위해 고전제어기법을 이용한 자동비행 알고리즘과 PN Guidance를 이용한 유 도명령을 생성하여 모의 훈련을 할 수 있는 시뮬 레이션 프로그램을 구성하였다.

본 연구를 통해 AIM-120B 모델의 미사일 모 의 발사 시뮬레이션을 구성 하였으며 차후 본 연 구결과를 검증 및 보완하여 비행제어 컴퓨터에 탑재 할 수 있도록 코딩 한다면 실제 비행 훈련 시 운용 가능한 시뮬레이터 개발에 이뤄질 것으 로 판단된다.

\section{후 기}

본 논문은 2단계 $\mathrm{BK} 21$ 사업단과 (주)한국항공우 주산업, 그리고 지식경제부 및 정보통신산업진흥 원의 대학 IT연구센터 지원사업의 연구결과로 수
행되었으며 (NIPA-2009-(C1090-0904-0001)) 지원 에 감사드립니다.

\section{참고문헌}

1) NASA Technical Memorandum, "The Analysis of a Generic Air-to-Air Missile Simulation Model”, June 1994.

2) Peter H.Zipfel, "Modeling and Simulation of Aerospace Vehicle Dynamics”, AIAA Education series.

3) Almer B. Galloway, "Joint Service Endgame Model(JSEM)", The 3rd ROK-US Munitions Effectiveness Seminar Vol. I, pp. 1080-1104, May 1990.

4) Almer B. Galloway, "Missile Debris as a Damage Mechanism", The 3rd ROK-US Munitions Effectiveness Seminar, Vol. I, pp. 1194- 1210, May 1990.

5) T.O-34-16C 자료 (F 16 전투기 기술지시서)

6) Dept. of U.S Army, "Missile Flight Simulation Part One; Surface-to- air Missiles", Military Handbook 1211(MI), pp. 2-19, July 17, 1995. 